\title{
The Impact of Blood Pressure on Carotid Artery Stiffness and Wave Intensity in Patients with Resistant Hypertension after Renal Sympathetic Denervation
}

Dana Skultetyova $^{1^{*}}$, Slavomira Filipova ${ }^{1,2}$, Pavol Chnupa $^{1}$, Juraj Madaric ${ }^{1}$, Viliam Fridrich ${ }^{3}$, Martin Gocar ${ }^{3}$ and Ivan Vulev ${ }^{4}$

${ }^{1}$ Department of Cardiology and Angiology, National Institute of Cardiovascular Diseases, Pod Krasnou horkou 1, 83348 Bratislava, Slovakia

${ }^{2}$ Department of Cardiology and Angiology, Slovak Medical University, Faculty of Medicine, Pod Krasnou horkou 1, 83348 Bratislava, Slovakia

${ }^{3}$ Department of Invasive and Interventional Cardiology, National Institute of Cardiovascular Diseases, Pod Krasnou horkou 1, 83348 Bratislava, Slovakia

${ }^{4}$ Department of Diagnostic and Interventional Radiology, National Institute of Cardiovascular Diseases, Pod Krasnou horkou 1, 83348 Bratislava, Slovakia

*Corresponding author: Dana Skultetyova, Department of Cardiology and Angiology, National Institute of Cardiovascular Diseases, Pod Krasnou horkou 1, 83348 Bratislava, Slovakia; Tel: 421259320281; E-mail: skultety@nus.ch

Recevied date: May 26, 2014; Accepted date: July 05, 2014; Published date: July 12, 2014

Copyright: @ 2014 Skultetyova D, et al. This is an open-access article distributed under the terms of the Creative Commons Attribution License, which permits unrestricted use, distribution, and reproduction in any medium, provided the original author and source are credited.

\begin{abstract}
Objective: The study investigated the impact of renal sympathetic denervation on office blood pressure and ambulatory blood pressure monitoring in patients with resistant hypertension. We evaluated whether a decrease in blood pressure may improve local carotid stiffness and parameters of wave intensity.

Methods: Renal sympathetic denervation was performed in 17 patients (age $55 \pm 9$ years) with true resistant hypertension. Measurements of carotid stiffness and wave intensity were performed using ultrasound combined with echo-tracking.

Results: We found significantly improved office systolic blood pressure changes 1 month $(p=0.023)$ and together with pulse pressure changes at the 6 month follow up $(p=0.041 ; p=0.016)$. Changes in systolic blood pressure during the daytime were significantly decreased at 1 month and diastolic blood pressure changes during the daytime were significantly reduced at 1 and 3 months. Stiffness parameters beta stiffness and pressure-strain elastic modulus were significantly reduced $(p=0.04 ; p=0.03)$ and arterial compliance was increased $(p=0.03)$, especially 1 and 3 months. The changes in negative area were significantly reduced after 1 month $(p=0.041)$ and the ejection period was significantly increased at the 6 month follow-up $(p=0.011)$. According to linear regression analysis systolic blood pressure correlated positively with the beta stiffness, pressure-strain elastic modulus, pulse wave velocity, and negatively with arterial compliance.
\end{abstract}

Conclusions: We found significantly lower office blood pressure as well as blood pressure from ambulatory blood pressure monitoring in patients with resistant hypertension 6 months after renal sympathetic denervation. The decrease in blood pressure was followed by improvement of carotid stiffness and wave intensity. That may be reflected in enhancement of ventricular-arterial coupling.

Keywords: Carotid stiffness; Renal sympathetic denervation; Resistant hypertension; Wave intensity analysis

\section{Summary}

The study investigated the impact of renal sympathetic denervation on blood pressure, carotid stiffness and wave intensity in 17 patients with resistant hypertension. We found improved blood pressure and stiffness parameters. Negative area was reduced and the ejection period increased.

\section{Introduction}

In recent years many authors have pointed out that arterial stiffness is considered to be an independent predictor of total and cardiovascular (CV) morbidity and mortality [1]. Arterial stiffening is closely related to age and arterial hypertension $(\mathrm{AH})$, together with $\mathrm{CV}$ risk factors involved in the progression of stiffness. Recently published ESH/ESC Guidelines for the diagnosis and treatment of hypertension recommended the assessment of arterial stiffness as evidence of target organ damage [2]. Arterial stiffening should be considered together with cardiac function, as it is known that the interaction between the heart and the arterial system, the "ventricular-arterial (V-A) coupling", could be the key factor in CV performance [3].

Resistant hypertension (RH) is defined when a therapeutic strategy that includes appropriate lifestyle measures plus a diuretic and two other antihypertensive drugs belonging to different classes at adequate doses fails to lower systolic BP and diastolic BP levels to $<140$ and 90 $\mathrm{mmHg}$, respectively. The prevalence has been reported to range from 5 to $30 \%$ of the overall hypertensive population, with the incidence of true $\mathrm{RH}$ less than $10 \%$ according to the latest ESH/ESC Guidelines [2]. This form of $\mathrm{AH}$ is characterized by excessive activity in the sympathetic nervous system. Interventional treatment with catheterbased renal sympathetic denervation (RDN) has been shown to be a promising and available therapeutic approach [4]. Several studies have reported the blood pressure (BP) lowering effect of RDN [5,6]. Until now, only a few studies have detected the possible favourable effect of $\mathrm{RDN}$ on arterial stiffness and central hemodynamics $[7,8]$. 
Citation: Skultetyova D, Filipova S, Chnupa P, Madaric J, Fridrich V, et al. (2014) The Impact of Blood Pressure on Carotid Artery Stiffness and Wave Intensity in Patients with Resistant Hypertension after Renal Sympathetic Denervation. J Hypertens 3: 157. doi: 10.4172/2167-1095.1000157

Page 2 of 6

The aim of the presented study was to determine the impact of $\mathrm{RDN}$ on office BP and ambulatory BP monitoring (ABPM) in patients with RH. Subsequently, we evaluated whether a decrease in BP has a positive effect on carotid stiffness as well as on V-A coupling using wave intensity analysis.

\section{Methods}

\section{Patients}

Between March 2012 and March 2013 we performed RDN in 17 patients (age $55 \pm 9$ years, $\mathrm{M}: \mathrm{F}=12: 5$ ) with true $\mathrm{RH}$ at the National Institute of Cardiovascular Disease (NUSCH) in Bratislava. The procedure was approved by the Ethics Committee of NUSCH. All physicians on the RDN team have received the international certificate for RDN (University of Heidelberg, Germany). In Slovakia RDN procedure is covered by the health insurance. All patients signed an informed consent.

The baseline characteristics of the patients are shown in Table 1. All patients fulfilled the eligibility criteria for RDN [2,9]. The patients were followed at 1, 3 and 6 months after the procedure. Three patients failed the follow-up at 3 and 6 months (causes unrelated to RDN). Routine blood tests, focused mainly on kidney functions, and renal duplex ultrasound examinations were performed during each visit. Control computed tomographic angiogram was performed one month after RDN. Echocardiography was performed immediately before $\mathrm{RDN}$ and at the 6 month follow-up.

\begin{tabular}{|c|c|c|}
\hline Parameter, unit & $\begin{array}{l}\text { Baseline } \\
(n=17)\end{array}$ & $\begin{array}{l}6 \text { months after } \\
\operatorname{RDN}(n=14)\end{array}$ \\
\hline Age $\pm S D$ (years) & $55 \pm 9$ & \\
\hline Men/Women (n) & $12 / 5$ & $9 / 5$ \\
\hline $\mathrm{BMI}\left(\mathrm{kg} / \mathrm{m}^{2}\right)$ & $36 \pm 6$ & \\
\hline Type 2 diabetes mellitus [n (\%)] & $4(23)$ & \\
\hline Hyperlipidemia [n (\%)] & $10(59)$ & \\
\hline CAD [n (\%)] & $2(12)$ & \\
\hline Antihypertensive drugs: $n$ & $6(5-7)$ & $6(5-8)$ \\
\hline Beta-blockers (\%) & 82 & 79 \\
\hline RAS blockers (\%) & 100 & 100 \\
\hline Calcium antagonists (\%) & 100 & 86 \\
\hline Diuretics (\%) & 94 & 93 \\
\hline Aldosterone antagonists (\%) & 35 & 36 \\
\hline Other antihypertensive drugs (\%) & 100 & 100 \\
\hline Heart rate (b.p.m.) & $67 \pm 13$ & $62 \pm 10$ \\
\hline eGFR (mL/min per $\left.1.73 \mathrm{~m}^{2}\right)$ & $81.9 \pm 19$ & $78 \pm 8$ \\
\hline LVEF (\%) & $63 \pm 9$ & $62 \pm 9$ \\
\hline
\end{tabular}

Table 1: General patient's characteristics, Data are expressed as means \pm SEM; BMI: Body Mass Index; CAD: Coronary Artery Disease; RAS: Renin-Angiotensin-System; eGFR: Calculated Glomerular Filtration
Rate; LVEF: left Ventricular Ejection Fraction; RDN: Renal Sympathetic Denervation

\section{BP measurements}

The office BP was measured in a supine position on the left brachial artery during ultrasound examination with an automatic oscillometric device Microlife BP100 PLUS (Microlife AG, Switzerland). All patients underwent ABPM using a validated SunTech-Oscar device (SunTech Medical, Inc., New Carolina, USA). BP measurements were taken at baseline before RDN and during each visit at follow-up.

\section{High resolution echo-tracking of common carotid arteries}

Measurement of carotid stiffness was performed with ALOKA Prosound Alpha 10 equipment (ALOKA Co., Ltd., Tokyo, Japan). This unit is equipped with an integrated and automated ultrasound, Doppler and an echo-tracking system. The echo-tracking system allowed real-time measurement of the diameter changes between the near and far wall of the common carotid artery (CCA). On the basis of experimental studies have been demonstrated that arterial pressure waveforms and diameter-change waveforms are similar $[10,11]$. Sugawara and coworkers [12] reported in humans the similarity between carotid arterial pressure waveforms measured with a cathetertipped micromanometer and carotid arterial diameter-change waveforms measured by echo-tracking. Brachial systolic and diastolic $\mathrm{BP}$ was used to calibrate the maximum and minimum values of the diameter-change waveforms. We used 5 consecutive beats to obtain a representative waveform.

The stiffness parameters were measured on both sides of the CCA in its longitudinal axis and after applying echo-tracking to the adventitia of the near and far wall. The following stiffness values were measured $[3,13]$ :

Stiffness index (beta), calculated from changes in vessel diameter and BP:

\section{$\operatorname{Beta}=\operatorname{In}(\mathrm{Ps} / \mathrm{Pd}) /[(\mathrm{Ds}-\mathrm{Dd}) / \mathrm{Dd}]$}

Where: In=the logarithm, Ps=systolic BP, Pd=diastolic BP,

$\mathrm{Ds}=$ arterial systolic diameter, $\mathrm{Dd}=$ arterial diastolic diameter

Pressure-strain elasticity modulus (Ep), an index of vessel elasticity, calculated from changes in vessel diameter and BP:

\section{$\mathrm{Ep}=(\mathrm{Ps}-\mathrm{Pd}) /[(\mathrm{Ds}-\mathrm{Dd}) / \mathrm{Dd}]$}

Arterial compliance (AC), an index of blood vessel compliance, calculated from the arterial cross sectional area and $\mathrm{BP}$ :

\section{$\mathrm{AC}=\mathrm{Ad} / \mathrm{R}(\mathrm{Ps}-\mathrm{Pd})$}

Where: $\mathrm{Ad}=$ the area under the BP diastolic decay curve from endsystole to end-diastole,

$\mathrm{R}=$ total peripheral resistance, $\mathrm{Ps}=$ the end-systolic $\mathrm{BP}, \mathrm{Pd}=$ the enddiastolic BP

One-point pulse wave velocity (PWV), calculated from the time delay between two adjacent distension waveforms from the water hammer equation for forward traveling waves using the $\beta$-stiffness parameter

AIx-augmentation index, calculated as the ratio between the augmentation pressure (AP) and PP (pulse pressure): 
Citation: Skultetyova D, Filipova S, Chnupa P, Madaric J, Fridrich V, et al. (2014) The Impact of Blood Pressure on Carotid Artery Stiffness and Wave Intensity in Patients with Resistant Hypertension after Renal Sympathetic Denervation. J Hypertens 3: 157. doi: 10.4172/2167-1095.1000157

Page 3 of 6

\section{$\mathrm{AIx}=\mathrm{AP} / \mathrm{PP}$}

Stiffness values were assessed at baseline and during each visit after RDN. During the ultrasound examination, we evaluated parameters of wave intensity (WI) too. The WI methodology provided us with information about the forward and backward travelling waves.

The time-normalized WI is the product of derivatives of $\mathrm{P}(\mathrm{BP})$ and $\mathrm{U}$ (blood velocity) with respect to time [13]:

\section{$\mathrm{WI}=(\mathrm{dP} / \mathrm{dt}) \times(\mathrm{dU} / \mathrm{dt})$}

Two indices of intensity can be derived, W1 and W2. The first index, W1, appears during early systole. There is evidence that W1 correlates with the maximum rate of left ventricular () pressure. The second index, W2, occurs towards the end of ejection. It is known that W2 relates to the ability of LV to actively stop aortic blood flow, and correlates with the time constant of relaxation [14]. The negative area parameter (NA) indicates the effects of reflected waves. The interval between the R wave on ECG and the peak of W1 (R-W1) is known as the pre-ejection period and the interval between the peaks $\mathrm{W} 1$ and $\mathrm{W} 2$ (W1-W2) as the ejection time (Figure 1) [13].

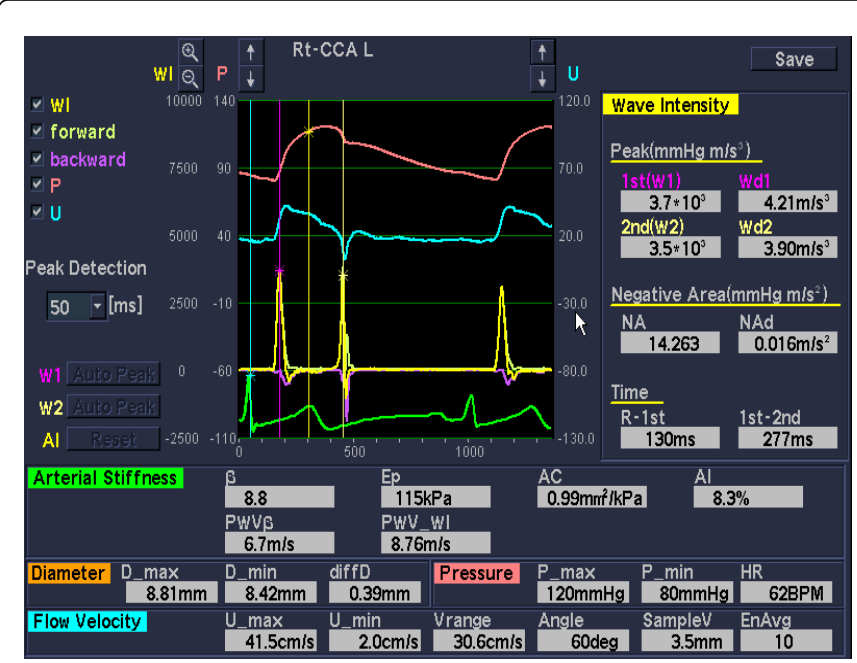

Figure 1: Automated assessment of carotid arterial wave intensity

\section{Catheter-based renal denervation}

A radiofrequency ablation catheter (Catheter Symplicity; Medtronic Ardian Inc., California, ) was advanced into each renal artery via femoral access. Low-power radiofrequency treatments were applied along the length of both main renal arteries as described elsewhere $[15,16]$. Patients were given heparin in an i.v. bolus to achieve a prolonged activated clotting time. Intra-procedural diffuse visceral pain was managed with i.v. anxiolytics and narcotics. We have not observed serious intra-procedural or peri-procedural complications. No important adverse events related to the procedure were noted in any of the treated patients during the follow-up.

\section{Statistical analysis}

Demographic characteristics, systolic BP, diastolic BP and all other analysed parameters were summarised with descriptive statistics, including mean and standard deviation (SD) for continuous variables, and frequency and percentage for categorical variables. The statistical significance of changes in continuous parameters over time was analysed by mean of the Wilcoxon Signed Rank test for dependent data. Spearman rank correlation was used to assess whether there was a relationship between variables. Using the linear regression model we examined the simultaneous effects of systolic BP and PP on the other analysed parameters. All tests were two-sided tests with the criteria set at $a=0.05$. A p-value of $<0.05$ was considered statistically significant.

\section{Results}

\section{Baseline Characteristics}

Table 1 presents baseline clinical characteristics of 17 patients with $\mathrm{RH}$ before RDN and at the 6 month follow-up.

\section{Blood pressure}

The changes in office systolic BP were significantly improved after 1 month and at the 6 month follow-up. We found significant changes in pulse pressure (PP) 6 months after RDN too (Figure 2).

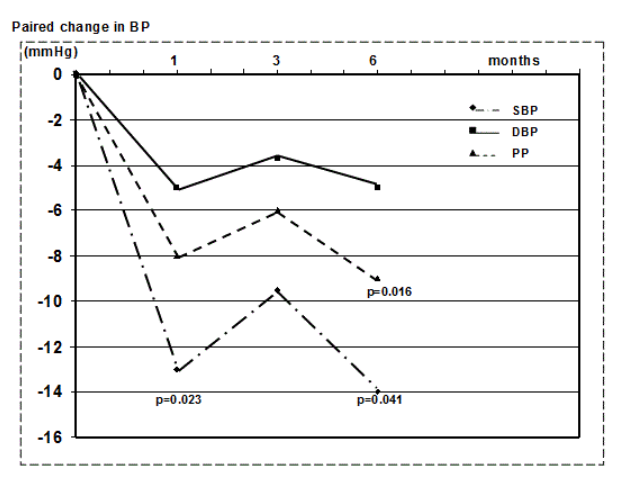

Figure 2: Paired changes in office systolic, diastolic and pulse pressure 6 months after renal sympathetic denervation, $\mathrm{BP}=\mathrm{Blood}$ Pressure; SBP=Systolic Blood Pressure; DBP=Diastolic Blood Pressure; $\mathrm{PP}=\mathrm{Pulse}$ pressure

Changes in systolic BP during the daytime derived from ABPM were significantly decreased at 1 month and diastolic BP changes during the daytime were significantly reduced at 1 and 3 months after the procedure as well (Table 2).

\begin{tabular}{|l|c|c|c|c|c|c|}
\hline & \multicolumn{3}{|l|}{ Paired changes } & \multicolumn{3}{|c|}{ P-value (two sided test) } \\
\hline Months & 1 & 3 & 6 & 1 & 3 & 6 \\
\hline SBP daytime & -13 & -9 & -8 & 0.026 & 0.14 & 0.162 \\
\hline (mmHg) & \pm 20 & \pm 20 & \pm 20 & \multicolumn{4}{|l|}{} \\
\hline SBP night-time & -2 & 4 & 7 & 0.733 & 0.724 & 0.396 \\
\hline (mmHg) & \pm 19 & \pm 25 & \pm 24 & & \\
\hline DBP daytime & -12 & -10 & -8 & 0.003 & 0.036 & 0.263 \\
\hline (mmHg) & \pm 19 & \pm 19 & \pm 22 & & \\
\hline DBP night-time & -1 & 0 & 3 & 0.426 & 0.937 & 0.594 \\
\hline (mmHg) & \pm 9 & \pm 13 & \pm 14 & \multicolumn{5}{|l|}{} \\
\hline
\end{tabular}


Citation: Skultetyova D, Filipova S, Chnupa P, Madaric J, Fridrich V, et al. (2014) The Impact of Blood Pressure on Carotid Artery Stiffness and Wave Intensity in Patients with Resistant Hypertension after Renal Sympathetic Denervation. J Hypertens 3: 157. doi: 10.4172/2167-1095.1000157

Page 4 of 6

\begin{tabular}{|l|c|c|c|c|c|c|}
\hline PP daytime & -5 & -3 & -5 & 0.14 & 0.345 & 0.234 \\
\hline (mmHg) & \pm 14 & \pm 14 & \pm 13 & \multicolumn{4}{|c|}{} \\
\hline PP night-time & -2 & 1 & 0 & 0.363 & 0.959 & 0.666 \\
\hline (mmHg) & \pm 9 & \pm 12 & \pm 11 & \multicolumn{4}{|c|}{} \\
\hline
\end{tabular}

Arterial Compliance; Aix: Augmentation Index; PWV: One-Point Pulse Wave Velocity

The changes in NA were significantly reduced after one month and significantly increased in W1-W2 at the 6 month follow-up (Table 4).

Table 2: Paired changes in ambulatory blood pressure monitoring before and after renal sympathetic denervation. Data are expressed as means \pm SD; SBP: Systolic Blood Pressure; DBP: Diastolic Blood Pressure; PP: Pulse Pressure

\section{Indices of carotid stiffness and wave intensity}

Stiffness indices were changed on both sides of the CCA; therefore, we evaluated the results of the right CCA. The changes in Ep were significantly reduced and in index AC increased at 1 month after RDN. The changes in beta and Ep values were significantly decreased after 3 months too. The changes in PWV declined slightly during the 3 months. AIx values, on the contrary, did not change significantly during this period (Table 3).

\begin{tabular}{|c|c|c|c|c|c|c|}
\hline & \multicolumn{3}{|l|}{ Paired changes } & \multicolumn{3}{|c|}{ P-value (two sided test) } \\
\hline Months & 1 & 3 & 6 & 1 & 3 & 6 \\
\hline Beta & -1.4 & -1.5 & -0.6 & 0.162 & 0.041 & 0.53 \\
\hline$(\%)$ & \pm 3.5 & \pm 3.3 & \pm 3.8 & \multicolumn{4}{|l|}{} \\
\hline $\mathbf{E p}$ & -35 & -36 & -7 & 0.039 & 0.033 & 0.594 \\
\hline $\mathbf{( k P a )}$ & \pm 58 & \pm 65 & \pm 83 & & \\
\hline $\mathbf{A C}$, & 0.11 & 0.12 & 0.05 & 0.03 & 0.069 & 0.167 \\
\hline $\mathbf{( m m} / \mathbf{k P a})$ & \pm 0.19 & \pm 0.23 & \pm 0.19 & & \\
\hline $\mathbf{A l x}$ & 2.4 & 5.8 & 2 & 0.364 & 0.637 & 0.753 \\
\hline & \pm 9.5 & \pm 16.8 & \pm 10.5 & \multicolumn{5}{|l|}{} \\
\hline $\mathbf{P W V}$ & -0.5 & -0.6 & -0.1 & 0.099 & 0.169 & 0.593 \\
\hline $\mathbf{( m / s )}$ & \pm 1.1 & \pm 1.8 & \pm 2.2 & \multicolumn{5}{|l|}{} \\
\hline
\end{tabular}

Table 3: Paired changes in indices of carotid artery stiffness before and after renal sympathetic denervation. Data are expressed as means \pm SD; Beta: Stiffness Index; Ep: Pressure-Strain Elasticity Modulus; AC:

\begin{tabular}{|c|c|c|c|c|c|c|}
\hline \multirow[b]{2}{*}{ Months } & \multicolumn{3}{|c|}{ Paired changes } & \multicolumn{3}{|c|}{ P-value (two sided test) } \\
\hline & 1 & 3 & 6 & 1 & 3 & 6 \\
\hline w1 & 0.2 & 6.5 & -6.6 & 0.57 & 0.239 & 0.328 \\
\hline$\left(\mathrm{mmHgm} / \mathrm{s}^{3}\right)$ & \pm 27.3 & \pm 36 & \pm 22.5 & & & \\
\hline w2 & -0.4 & -1.2 & -1.3 & 0.691 & 0.182 & 0.059 \\
\hline$\left(\mathrm{mmHg} \mathrm{m} / \mathrm{s}^{3}\right)$ & \pm 2.6 & \pm 2.3 & \pm 2.0 & & & \\
\hline NA & -21 & 46 & -36 & 0.041 & 0.388 & 0.345 \\
\hline$\left(\mathrm{mmHg} \mathrm{m} / \mathrm{s}^{2}\right)$ & \pm 160 & \pm 212 & \pm 122 & & & \\
\hline R-W1 & 34 & 2 & -3 & 0.003 & 0.722 & 0.255 \\
\hline (ms) & \pm 27 & \pm 32 & \pm 19 & & & \\
\hline W1-W2 & -3 & 11 & 27 & 0.293 & 0.071 & 0.011 \\
\hline (ms) & \pm 35 & \pm 19 & \pm 29 & & & \\
\hline
\end{tabular}

Table 4: Paired changes in indices of wave intensity before and after renal sympathetic denervation

Data are expressed as means $\pm \mathrm{SD}$; Wave intensity: first peak W1 correlates with maximum rate of left ventricular pressure; second peak W2 correlates with the time constant of left ventricular relaxation; NA: Negative Area, determines the effects of reflected waves; R-W1: the interval between the R wave on ECG and the peak of W1 (R-W1) corresponds to pre-ejection period; W1-W2: corresponds to ejection time.

Using the Spearman rank correlation, we found significant correlations between office $\mathrm{BP}$ and the stiffness indexes. At the baseline correlated only PP with Ep $\left(\mathrm{r}_{\mathrm{s}}=0.499, \mathrm{p}=0.041\right)$. At the 6 months SBP and DBP correlated positive with indexes Ep, PWV and negative with AC (Table 5). Similarly we found positive correlations between the changes in SBP, DBP and the changes in indexes EP, PWV (Table 6). The changes in PP correlated positive with changes in indexes Ep and PWV 6 months after RDN (Table 6, Figure 3).

\begin{tabular}{|l|l|l|l|l|l|l|l|l|l|l|}
\hline & beta & & Ep & & AC & & Alx & & PWV & \\
\hline & $\mathbf{r}_{\mathrm{s}}$ & $\mathbf{p}$ & $\mathbf{r}_{\mathrm{s}}$ & $\mathbf{p}$ & $\mathbf{r}_{\mathrm{s}}$ & $\mathbf{p}$ & $\mathbf{r}_{\mathrm{s}}$ & $\mathbf{p}$ & $\mathbf{r}_{\mathrm{s}}$ & $\mathbf{p}$ \\
\hline SBP & 0.398 & 0.159 & 0.613 & 0.02 & -0.674 & 0.008 & 0.175 & 0.55 & 0.559 & 0.038 \\
\hline DBP & 0.346 & 0.226 & 0.617 & 0.019 & -0.693 & 0.006 & 0.127 & 0.664 & 0.673 & 0.008 \\
\hline PP & 0.524 & 0.054 & 0.491 & 0.074 & -0.394 & 0.163 & 0.061 & 0.836 & 0.374 & 0.188 \\
\hline
\end{tabular}

Table 5: The correlations between carotid stiffness parameters and office blood pressure at 6 months after renal sympathetic denervation

SBP: Systolic Blood Pressure; DBP: Diastolic Blood Pressure; PP: Pulse Pressure; Beta: Stiffness Index; Ep: Pressure-Strain Elasticity
Modulus; AC: Arterial Compliance; PWV: One-Point Pulse Wave Velocity; AIx: Augmentation Index; RDN: Renal Sympathetic Denervation; $r_{s}=$ Spearman Rank Correlation Coefficient; $p=p$-value; 
Citation: Skultetyova D, Filipova S, Chnupa P, Madaric J, Fridrich V, et al. (2014) The Impact of Blood Pressure on Carotid Artery Stiffness and Wave Intensity in Patients with Resistant Hypertension after Renal Sympathetic Denervation. J Hypertens 3: 157. doi: 10.4172/2167-1095.1000157

Page 5 of 6

\begin{tabular}{|l|l|l|l|l|l|l|l|l|l|l|}
\hline & $\begin{array}{l}\text { Changes in } \\
\text { beta }\end{array}$ & & $\begin{array}{l}\text { Changes in } \\
\text { Ep }\end{array}$ & $\begin{array}{l}\text { Changes in } \\
\text { AC }\end{array}$ & $\begin{array}{l}\text { Changes in } \\
\text { Alx }\end{array}$ & $\begin{array}{l}\text { Changes in } \\
\text { PWV }\end{array}$ \\
\hline & $\mathbf{r}_{\mathrm{s}}$ & $\mathbf{p}$ & $\mathbf{r}_{\mathrm{s}}$ & $\mathbf{p}$ & $\mathbf{r}_{\mathrm{s}}$ & $\mathbf{p}$ & $\mathbf{r}_{\mathrm{s}}$ & $\mathbf{p}$ & $\mathbf{r}_{\mathrm{s}}$ & $\mathbf{p}$ \\
\hline Changes in SBP & 0.449 & 0.107 & 0.762 & 0.002 & -0.466 & 0.093 & 0.11 & 0.708 & 0.774 & 0.001 \\
\hline Changes in DBP & 0.471 & 0.089 & 0.74 & 0.002 & -0.482 & 0.081 & 0.075 & 0.799 & 0.782 & 0.001 \\
\hline Changes in PP & 0.424 & 0.13 & 0.737 & 0.003 & -0.513 & 0.061 & 0.015 & 0.958 & 0.701 & 0.005 \\
\hline
\end{tabular}

Table 6: The correlations between changes in carotid stiffness parameters and changes in office blood pressure at 6 months after renal sympathetic denervation

SBP: Systolic Blood Pressure; DBP: Diastolic Blood Pressure; PP: Pulse Pressure; beta: Stiffness Index; Ep: Pressure-Strain Elasticity Modulus; AC: Arterial Compliance; PWV: one-Point Pulse Wave Velocity; Aix: Augmentation Index; RDN: Renal Sympathetic Denervation; rs=Spearman Rank Correlation Coefficient; $p=p$-value;

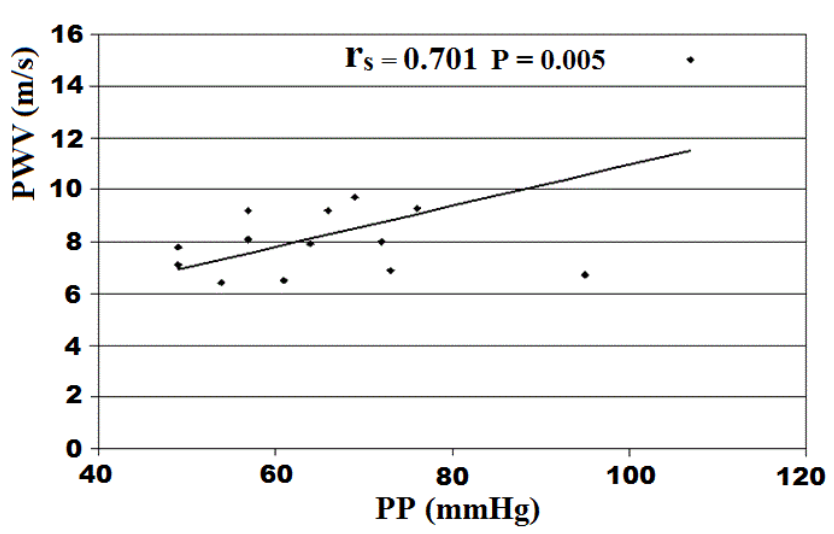

Figure 3: Correlation between changes in pulse pressure (PP) and changes in one point pulse wave velocity (PWV) in patients with resistant hypertension 6 months after renal sympathetic denervation. rs=Spearman rank correlation coefficient, coefficient above 0.5 represent a large association or relationship. $\mathrm{p}=\mathrm{p}$-value, $<0.05$ was considered statistically significant.

Office systolic BP and PP correlated to $\mathrm{W} 1\left(\mathrm{r}_{\mathrm{s}}=0.781, \mathrm{p}<0.0001\right.$; $\left.\mathrm{r}_{\mathrm{s}}=0.867, \mathrm{p}<0.0001\right)$ and to NA $\left(\mathrm{r}_{\mathrm{s}}=0.618, \mathrm{p}=0.011 ; \mathrm{r}_{\mathrm{s}}=0.576, \mathrm{p}=0.002\right)$ only at baseline.

Systolic BP during the night-time and PP during the daytime and night-time derived from ABPM correlated to index Ep only at baseline $\left(\mathrm{r}_{\mathrm{s}}=0.504, \mathrm{p}=0.047 ; \mathrm{r}_{\mathrm{s}}=0.556, \mathrm{p}=0.021 ; \mathrm{r}_{\mathrm{s}}=0.511, \mathrm{p}=0.043\right)$.

Linear regression analysis was used to detect the interrelations between office BP, carotid stiffness, and WI. Systolic BP correlated positively with the beta index $(\beta=0.18, p=0.01$; $95 \%$ CI $0.053-0.307)$ and with $\operatorname{Ep}(\beta=5.592, p<0.0001,95 \%$ CI 3.796-7.388), negatively with AC $(\beta=-0.009, p<0.0001,95 \%$ CI $-0.013-0.006)$, and positively with PWV ( $(=0.07, p=0.001,95 \%$ CI $0.034-0.106)$. We did not detect correlations with WI.

\section{Discussion}

In the study we have found significantly lower values of office BP as well as values of ABPM in patients with $\mathrm{RH}$ at the 6 month after RDN. In the same period, we found improvement in carotid stiffness values. Many factors are known to affect carotid stiffness, including low grade inflammation and age among others $[17,18]$. In this study we have focused on BP. Relationships between BP and stiffness indices have emphasized the impact of BP, particularly of systolic BP and PP, on carotid stiffness. Recent studies have reported that RDN improved BP as well as arterial stiffness. Brandt and co-workers [19] found significantly reduced carotid-femoral PWV in 110 patients 6 months after RDN. Other study demonstrated in responders an improvement of two-point PWV by $13.7 \% 6$ months after the procedure [8]. Most of the studies have used the method of applanation tonometry for the measurement of arterial stiffness. Very few studies were done with method of the local carotid artery stiffness measurement using the ultrasound with echo-tracking, but without an association with RDN. The main advantage of the echo-tracking method is that carotid stiffness is determined directly from the change in pressure and the change in volume without the use modeling of the circulation [20].

The mechanisms of BP reduction after RDN are not completely known. Reduced sympathetic activity after RDN is the main recognized mechanism responsible for lowering BP [21]. It is known that the procedure is followed by reduced efferent sympathetic stimulation, by lowering of norepinehrine spillover, by reduced plasma renin activity, and by increased natriuresis and renal blood flow. The decrease in renal afferent signalling is associated with lowering of central sympathetic activity [22]. We found significantly improved carotid stiffness parameters. We affirmed the relationships between BP values and stiffness parameters at 6 months after RDN. According to these results we may suppose that the BP reduction together with modification of sympathetic tone after RDN may lead to attenuation of carotid stiffening.

The clinical effectiveness of the RDN procedure is mainly known from the Simplicity Clinical Trial Program. To date Simplicity HTN-1 and Simplicity HTN-2 are the largest trials on this topic, which have confirmed the effect of RDN on lowering BP $[16,23]$. On the other hand, the results of the Simplicity HTN-3 trial did not show a significant reduction of office systolic BP as compared with a sham control [24]. Other single centre studies have mostly included a small number of patients. The RDN method raises a number of questions, the correct clinical selection of patients who will the real benefit from RDN being one of the key issues [25].

In our previous study we found increased carotid stiffness indices in hypertensive patients and, based on the relations between BP and 
Citation: Skultetyova D, Filipova S, Chnupa P, Madaric J, Fridrich V, et al. (2014) The Impact of Blood Pressure on Carotid Artery Stiffness and Wave Intensity in Patients with Resistant Hypertension after Renal Sympathetic Denervation. J Hypertens 3: 157. doi: 10.4172/2167-1095.1000157

Page 6 of 6

indices of carotid stiffness as well as WI, we assumed an effect of BP on V-A coupling [26]. In the present study we have used WI to analyse VA coupling in patients after RDN. The NA index, which signifies reflections from the cerebral circulation, was significantly reduced at 1 month after RDN. On the other hand, we found the relation between $\mathrm{BP}$ and NA only at the baseline. Systolic BP and PP correlated with NA and with W1. On the basis on these findings, we may consider that the relationship between $\mathrm{BP}$ and WI may reflect the impact of $\mathrm{BP}$ on the reflected waves returning to the heart and consequently affect the rise in LV pressure. There is evidence that increased stiffness in conduit arteries is associated with early arrival of reflected waves to the proximal aorta during mid-to-late systole. The load caused by the reflected wave may result in shortening of the ejection period [27]. We observed a significantly prolonged W1-W2 index 6 months after RDN. Therefore, we may assume that the decrease in BP was followed by a reduction in NA and consequently by prolongation of the LV ejection period. We suggest that improvement in carotid stiffness and WI may be reflected in the enhancement of $\mathrm{V}$-A coupling.

Some limitations of this study may be noted. We have evaluated a relatively small group of patients with $\mathrm{RH}$ (17 subjects) and over a shorter follow-up period (6 months). For these reasons we have not analyse the impact of BP value on carotid stiffness in responders and non-responders. It is therefore necessary to continue to monitor our patients for a longer period.

\section{Conclusion}

We have found improvement in office BP as well as ABPM in patients with RH 6 months after RDN. The decrease in BP was followed by improvement of carotid stiffness and WI. That may be reflected in the enhancement of $\mathrm{V}$-A coupling.

\section{References}

1. Mitchell GF, Hwang SJ, Vasan RS, Larson MG, Pencina MJ et al. (2010) Arterial stiffness and cardiovascular events: the Framingham Heart Study. Circulation 121: 505-511.

2. Mancia G, Fagard R, Narkiewicz K, Redón J, Zanchetti A et al. (2013) 2013 ESH/ESC guidelines for the management of arterial hypertension. The Task Force for the management of arterial hypertension of the European Society of Hypertension (ESH) and of the European Society of Cardiology (ESC). J Hypertens 31:1281-1357.

3. Antonini-Canterin F, Carerj S, Di Bello V, Di Salvo G, La Carrubba S et al. (2009) Arterial stiffness and ventricular stiffness: a couple of diseases or a coupling disease? A review from the cardiologist's point of view. Eur J Echocardiogr 10: 36-43.

4. Schlaich MP, Sobotka PA, Krum H, Whitbourn R, Walton A et al. (2009) Renal denervation as a therapeutic approach for hypertension: novel implications for an old concept. Hypertension 54: 1195-1201.

5. Bertog SC, Sobotka PA, Sievert H (2012) Renal denervation for hypertension. JACC Cardiovasc Interv 5: 249-258.

6. Grassi G, Mancia G (2013) Renal nerve ablation as a tool for studying the interactions between arterial stiffness, blood pressure and sympathetic drive: weight of the evidence. J Hypertens 31: 1782-1784.

7. Hering D, Lambert EA, Marusic P, Ika-Sari C, Walton AS et al. (2013) Renal nerve ablation reduces augmentation index in patients with resistant hypertension. J Hypertens 31: 1893-1900.

8. Mortensen K, Franzen K, Himmel F, Bode F, Schunkert H et al. (2012) Catheter-based renal sympathetic denervation improves central hemodynamics and arterial stiffness: a pilot study. J Clin Hypertens (Greenwich) 14: 861-870.

9. Schmieder RE, Redon J, Grassi G, Kjeldsen SE, Mancia G et al. (2012) ESH position paper: renal denervation-an interventional therapy of resistant hypertension. J of Hypertens 30: 837-841

10. Barnett GO, Mallos AJ, Shapiro A (1961) Relationship of aortic pressure and diameter in the dog. J Appl Physiol 16: 545-548.

11. Patel DJ, De Freitas FM, Greenfield JC Jr, Fry DL (1963) Relationship of radius to pressure along the aorta in living dogs. J Appl Physiol 18: 1111-1117.

12. Sugawara M, Niki K, Furuhata H, Ohnishi S, Suzuki S (2000) Relationship between the pressure and diameter of the carotid artery in humans. Heart Vessels 15: 49-51.

13. Sugawara M, Niki K, Ohte N, Okada T, Harada A (2009) Clinical usefulness of wave intensity analysis. Med Biol Eng Comput 47: 197-206.

14. Ohte N, Narita H, Sugawara M, Niki K, Okada T et al. (2003) Clinical usefulness of carotid arterial wave intensity in assessing left ventricular systolic and early diastolic performance. Heart Vessels 18: 107-111.

15. Krum H, Schlaich M, Whitbourn R, Sobotka PA, Sadowski J et al. (2009) Catheter-based renal sympathetic denervation for resistant hypertension: a multicentre safety and proof-of-principle cohort study. Lancet 373: 1275-1281.

16. Symplicity HTN-2 Investigators, Esler MD, Krum H, Sobotka PA, Schlaich MP, et al. (2010) Renal sympathetic denervation in patients with treatment-resistant hypertension (The Symplicity HTN-2 Trial): a randomised controlled trial. Lancet 376: 1903-1909.

17. van Bussel BC, Henry RM, Schalkwijk CG, Dekker JM, Nijpels G, et al. (2012) Low-grade inflammation, but not endothelial dysfunction, is associated with greater carotid stiffness in the elderly: the Hoorn Study. J Hypertens 30: 744-752.

18. Skultety J, Labas P, Durdik S. (1996) Zytokinaktivität bei Patienten mit gastrointestinalen Karzinomen. MMV Taschenbuch Systematische Enzymtherapie Munchen, Medizin Verlag: 251-253

19. Brandt MC, Reda S, Mahfoud F, Lenski M, Böhm M, et al. (2012) Effects of renal sympathetic denervation on arterial stiffness and central hemodynamics in patients with resistant hypertension. J Am Coll Cardiol 60: 1956-1965

20. Laurent S, Cockcroft J, Van Bortel L et al. (2006) Expert consensus document on arterial stiffness: methodological issues and clinical application. Eur Heart J 27: 2588-2605

21. Krum H, Sobotka P, Mahfoud F, Böhm M, Esler M et al. (2011) Devicebased antihypertensive therapy: therapeutic modulation of the autonomic nervous system. Circulation 123: 209-215.

22. Mafeld S, Vasdev N, Haslam P (2012) Renal denervation for treatmentresistant hypertension. Ther Adv Cardiovasc Dis 6: 245-258.

23. Symplicity HTN-1 Investigators (2011) Catheter-based renal sympathetic denervation for resistant hypertension: durability of blood pressure reduction out to 24 months. Hypertension 57: 911-917.

24. Bhatt DL, Kandzari DE, O'Neill WW, D'Agostino R, Flack JM et al (2014) A controlled trial of renal denervation for resistant hypertension. N Engl J Med 370: 1393-1401.

25. Schlaich MP, Esler MD, Fink GD, Osborn JW, Euler DE (2014) Targeting the sympathetic nervous system: critical issues in patient selection, efficacy, and safety of renal denervation. Hypertension 63: 426-432.

26. Skultetyova D, Filipova S, Chnupa P (2013) Effect of blood pressure on carotid stiffness and ventricular-arterial coupling. Cardiol Lett 22: 20-27

27. Chirinos JA, Segers P (2010) Noninvasive evaluation of left ventricular afterload: part 2: arterial pressure-flow and pressure-volume relations in humans. Hypertension 56: 563-570. 